\title{
Stroke in Patients with Left Ventricular Assist Devices
}

\author{
Alyson R. Plecash ${ }^{a}$ Danielle Byrne ${ }^{b}$ Alana Flexman ${ }^{c}$ Mustafa Toma ${ }^{d}$ \\ Thalia S. Field ${ }^{\mathrm{a}} \mathrm{e}$ \\ ${ }^{a}$ Division of Neurology, University of British Columbia, Vancouver, BC, Canada; ${ }^{b}$ Division of Radiology, University of \\ British Columbia, Vancouver, BC, Canada; 'Division of Anesthesiology, University of British Columbia, Vancouver, BC, \\ Canada; ${ }^{d}$ Division of Cardiology, University of British Columbia, Vancouver, BC, Canada; eVancouver Stroke Program, \\ Vancouver Coastal Health, Vancouver, BC, Canada
}

\section{Keywords}

Stroke · Left ventricular assist device $\cdot$ Thrombosis ·

Hemorrhage

\begin{abstract}
Background: Left ventricular assist devices (LVADs) are artificial pumps used in end-stage heart failure to support the circulatory system. These cardiac assist devices work in parallel to the heart, diverting blood from the left ventricle through an outflow graft and into the ascending aorta. LVADs have allowed patients with end-stage heart failure to live longer and with improved quality of life compared to best medical therapy alone. However, they are associated with significant risks related to both thrombosis and bleeding in this medically complex patient population. As LVADs continue to be used more widely, stroke neurologists need to become familiar with the unique physical exam and vascular imaging findings associated with this population. Summary: Reported rates of LVAD-associated stroke at 2 years post-implantation range from 10 to $30 \%$, which is significantly higher than in age-matched controls. There are approximately equal rates of ischemic and hemorrhagic strokes, and rates are highest during the peri-implantation period and in the first year of therapy. Risk factors associated with ischemic and hemorrhagic stroke in this cohort can be
\end{abstract}

karger@karger.com

(c) 2021 S. Karger AG, Basel

www.karger.com/ced

Karger" grouped into treatment-related factors, including specific devices and antithrombotic/anticoagulation strategy, and patient-related factors. Evidence for reperfusion therapy for acute stroke in this population is limited. Intravenous tissue plasminogen activator (IV-tPA) is often contraindicated as events may occur in the perioperative setting, or in the context of therapeutic anticoagulation. Endovascular therapy with successful recanalization is reported, but there is little experience documented in the published literature. Key messages: LVAD use is increasingly common. Given the high associated risks of stroke, neurologists will need to become increasingly familiar with an approach to assessment and therapy for LVAD patients with cerebrovascular issues.

(c) 2021 S. Karger AG, Basel

\section{Introduction}

Left ventricular assist devices (LVADs) are artificial pumps used in end-stage heart failure to support the circulatory system. This technology has been in development for over 50 years, with extracorporeal oxygenation via a heart-lung machine first used in surgery in the early 1950s [1]. From there, the total artificial heart, a metal dual-chamber pump, was developed as a device to replace the heart. These machines were meant to bridge patients

Correspondence to:

Thalia S. Field, thalia.field@ubc.ca 
to cardiac transplant, and from this technology the LVAD was born. An LVAD is a cardiac assist device that works in parallel to the heart. The blood from the left ventricle is diverted, pumped, and then returned to circulation through the ascending (or, less commonly, the descending) aorta. The LVAD has gone through many iterations during its development, each of which has employed a unique pumping mechanism $[1,2]$. First-generation devices created pulsatile blood flow through membrane pumps. Second-generation devices were smaller and quieter, and used continuous-flow pumps that employed axial force to direct forward blood flow. Third-generation devices, also continuous pumps, employ centrifugal force dynamics to produce forward flow, but are even smaller and more durable than their second-generation counterparts [1].

Initially, LVADs were used in selected patients as destination therapy for refractory heart failure. Currently, LVADs are used for a number of different purposes in patients with end-stage heart failure, including as a bridge to transplant/transplant decision, support toward recovery of native cardiac function, or destination (i.e., permanent) therapy. The number of individuals using LVADs has increased accordingly. Following the FDA approval of LVAD use for destination therapy, Medicare data showed a $491 \%$ relative increase in the number of implantations between 2004 and 2010 in the US [3, 4]. Increasingly, implantations are being performed in older patients with comorbid disease, including chronic pulmonary or renal disease. Men using LVADs continue to outnumber women $[3,4]$.

This assistive technology improves survival, improves quality of life, and facilitates patient independence. With technological improvements, smaller, lighter peripherals such as system controllers can be worn to work and carried by more frail patients. Despite these meaningful benefits, there are serious complications associated with LVADs, including stroke, pump thrombosis, and infection. In particular, the risk of both hemorrhagic and ischemic stroke is high and estimated at $10-30 \%$ within 2 years of device implantation $[5,6]$, although 30 -day and 1 -year survival following implantation has improved dramatically in recent years [3]. Given the increasing use and broadening indications for LVADs and their associated high-risk of stroke, stroke neurologists should be familiar with the unique considerations in this patient group. Here, we review the epidemiology and pathophysiology of stroke in individuals with LVADs and review unique considerations in the assessment and management of stroke in this population.

\section{Epidemiology}

\section{Stroke Rates and Risk Factors}

Both ischemic and hemorrhagic stroke are common complications of LVADs, and stroke remains the commonest cause of death between 6 and 24 months postimplantation [7]. Although the bulk of clinical trial data suggest a preponderance toward ischemic stroke (Table 1), prospective registry data report ischemic and hemorrhagic stroke in equal proportions [15]. Previous research has identified a bimodal distribution of stroke risk, with a peak around the time of surgical insertion, and a second peak around 1 year post-implantation [16-19]. However, the stroke rate varies depending on device generation, with lower rates of stroke seen with further refinement of device technology [20].

The Interagency Registry for Mechanically Assisted Circulatory Support (INTERMACS registry registry) is a large prospective observational registry of both adults and children with LVADs, and has followed 9,489 patients receiving 10,285 continuous-flow LVADs between 2014 and 2017 . Overall, $16 \%$ of patients had one (85\%) or more (15\%) strokes, with ischemic and hemorrhagic events occurring with equal frequency, although the median follow-up period was not specified. The risk of stroke was $4 \%$ in the first month, rising to $9 \%$ in the first 6 months and $14 \%$ in the first year. Stroke was a major contributor to 6-month mortality, with survival after hemorrhagic stroke $<50 \%$, and $70 \%$ with ischemic stroke. While risk of first ischemic stroke was associated with an increased risk of subsequent ischemic and hemorrhagic stroke, those with incident hemorrhagic strokes were not at increased risk for recurrent hemorrhagic events [15].

Rates of stroke (expressed in events per patient year, EPPY) from major LVAD clinical trials are summarized in Table 1 (detailed trial summaries are included in online suppl. Table 1; for all online suppl. material, see www. karger.com/doi/10.1159/000517454). Stroke endpoints vary, with some investigators reporting all disabling stroke, while others reporting all events, and some but not all studies distinguishing between hemorrhagic and ischemic events. Further, it remains to be clarified in some studies as to whether hemorrhagic transformation of ischemic stroke may have been misclassified as a primary intracranial hemorrhage. In the MOMENTUM trial, the incidence of stroke that was associated with the HeartMate III was lower, with greater freedom from stroke than reported historically [14]. Current evidence suggests that stroke risk factors differ between the peri-implantation period versus later strokes, and ischemic versus hemorrhagic strokes. 
Table 1. Stroke rates from clinical trials in the LVAD population $[5,6,8-14]$

\begin{tabular}{|c|c|c|c|c|}
\hline Trial & Device intervention/comparison & \multicolumn{2}{|c|}{ Stroke event rate (event per patient year, EPPY) } & Duration of follow-up \\
\hline $\begin{array}{l}\text { HeartMate II destination } \\
\text { therapy }[10]\end{array}$ & $\begin{array}{l}\text { HeartMate II LVAD (Thoratec, } \\
\text { continuous-flow device) versus } \\
\text { HeartMate XVE LVAD (pulsatile-flow } \\
\text { device) with warfarin (INR target } 2-3 \text { ), } \\
\text { aspirin } 81 \text { mg daily and dipyridamole } 75 \\
\text { mg } 3 \text { TID }\end{array}$ & \multicolumn{2}{|c|}{$\begin{array}{l}\text { Timing not specified further within the first } 2 \text { years } \\
\text { HeartMate XVE LVAD: } \\
\text { Ischemic } 0.10 \\
\text { Hemorrhagic } 0.12 \\
\text { HeartMate II LVAD: } \\
\text { Ischemic } 0.06 \\
\text { Hemorrhagic } 0.07\end{array}$} & $\begin{array}{l}24 \text { months ( } 44 \% \text { of the } \\
\text { HeartMate II and } 27 \% \text { of the } \\
\text { HeartMate XVE groups died). } \\
\text { All but } 2 \text { in the HeartMate } \\
\text { XVE group crossed over to } \\
\text { the HeartMate II group given } \\
\text { need for reimplantation }\end{array}$ \\
\hline ADVANCE [11] & $\begin{array}{l}\text { HVAD versus any commercially available } \\
\text { LVAD with warfarin (INR target } 2-3 \text { ) and } \\
\text { aspirin } 81 \mathrm{mg} \text { daily }\end{array}$ & $\begin{array}{l}\text { HVAD: } \\
\text { Ischemic } 0.62 \\
\text { TIA } 0.18 \\
\text { Hemorrhagic } 0.26\end{array}$ & $\begin{array}{l}\text { HVAD: } \\
\text { Ischemic } 0.04 \\
\text { TIA } 0.06 \\
\text { Hemorrhagic } 0.06\end{array}$ & $\begin{array}{l}6 \text { months }(4.7 \% \text { of HVAD } \\
\text { patients had died and } 27 \% \\
\text { had received HT) }\end{array}$ \\
\hline $\begin{array}{l}\text { HeartMate III CE Mark, } \\
\text { follow-up [12] }\end{array}$ & $\begin{array}{l}\text { HeartMate III with VKA (INR target 2-3) } \\
\text { and aspirin 81-100 mg daily }\end{array}$ & \multicolumn{2}{|c|}{$\begin{array}{l}\text { Timing of events not specified further within the } \\
\text { first } 180 \text { days } \\
\text { Ischemic } 0.10 \\
\text { Hemorrhagic } 0.05\end{array}$} & $\begin{array}{l}24 \text { months (64\% remained on } \\
\text { LVAD support) }\end{array}$ \\
\hline ROADMAP [5] & $\begin{array}{l}\text { HeartMate II with warfarin (INR target } \\
2-3 \text { ) and aspirin daily versus optimal } \\
\text { medical therapy }\end{array}$ & \multicolumn{2}{|c|}{$\begin{array}{l}\text { Timing not specified further within the first year } \\
\text { HeartMate II LVAD: } \\
\text { Total } 0.09 \\
\text { Ischemic } 0.06 \\
\text { Hemorrhagic } 0.03 \\
\text { Medical: } \\
\text { Total } 0.03 \\
\text { Ischemic } 0.02 \\
\text { Hemorrhagic } 0.01\end{array}$} & $\begin{array}{l}24 \text { months ( } 62 \% \text { remained on } \\
\text { LVAD support) }\end{array}$ \\
\hline PREVENT [13] & $\begin{array}{l}\text { Nonrandomized. HeartMate II with } \\
\text { warfarin (INR target 2-2.5) } \pm \text { daily aspirin } \\
81-325 \mathrm{mg}\end{array}$ & \multicolumn{2}{|c|}{$\begin{array}{l}\text { Timing not specified further within first } 3 \text { months } \\
\text { HeartMate II: } \\
\text { Ischemic } 0.08 \\
\text { Hemorrhagic } 0.05\end{array}$} & $\begin{array}{l}6 \text { months ( } 5 \% \text { of received } \mathrm{HT} \\
\text { and } 11 \% \text { died) }\end{array}$ \\
\hline MOMENTUM 3 [14] & $\begin{array}{l}\text { HeartMate III with warfarin (INR target } \\
2-3 \text { ) and daily aspirin } 81-325 \mathrm{mg} \text { versus } \\
\text { HeartMate II with warfarin (INR target } \\
2-3 \text { ) and daily aspirin } 81-325 \mathrm{mg}\end{array}$ & \multicolumn{2}{|c|}{$\begin{array}{l}\text { Timing not specified within first } 6 \text { months } \\
\text { HeartMate III: } \\
\text { Total stroke } 0.08 \\
\text { HeartMate II: } \\
\text { Total stroke } 0.18\end{array}$} & $\begin{array}{l}24 \text { months ( } 53 \% \text { remained on } \\
\text { LVAD support) }\end{array}$ \\
\hline
\end{tabular}

VKA, vitamin K antagonist; HF, heart failure; HT, heart transplant; CF, continuous flow; PF, pulsatile flow; LVAS, left ventricular assist system; HVAD, HeartWare left ventricular assist device; LVADs, left ventricular assist devices. * "Neurologic dysfunction" composite of stroke, TIA, and encephalopathy. 


\section{Peri-Implantation Period}

The peri-implantation period is typically defined as the time during surgical implantation of LVAD devices, and the 30 days after surgery. Prior to implantation, the factors associated with stroke include lower cardiac output, higher LDH (a marker of hemolysis and a potent platelet activator) and higher systolic blood pressures [15]. Several risk factors for stroke have been identified in the peri-implantation period. In the INTERMACS registry, older age, centrifugal flow devices, and concomitant cardiac surgery were associated with higher rates of early stroke in the first month post-implantation. The hypercoagulable state secondary to surgery, coupled with inadequate anticoagulation/antithrombotic therapy during this high-risk postoperative period, as well as pump time, concurrent valve surgery, and perioperative atrial fibrillation are recognized risk factors for early ischemic stroke $[16,21,22]$. One prospective study of 477 patients found that the majority of patients with ischemic stroke within the first 14 days post-implantation (13/17) were either not on anti-thrombotic medication, or were on antiplatelet therapy with no anticoagulation or subtherapeutic anticoagulation [17]. A variety of subtypes of intracranial hemorrhage have been described during the peri-implantation period, and include subarachnoid, intracerebral and subdural hemorrhages. Subarachnoid hemorrhages were more frequent during the peri-implantation compared to the later period [16]. Rates of both early ischemic and hemorrhagic stroke are also associated with infection, particularly bacteremia or device pump infection [17].

\section{Chronic Period}

As in the general population, atrial fibrillation, hypertension, diabetes, prior stroke or myocardial infarction, and smoking, were associated with an increased risk of ischemic stroke in the LVAD population after 30 days following implantation. In the INTERMACS registry, later strokes were associated with female sex, severe diabetes, COPD and active smoking, centrifugal flow pumps, and repeated nonadherence to medical therapy [15]. Pump thrombosis has been identified as an additional risk factor for ischemic stroke, and infection in the pump or bloodstream is associated with chronic risks of ischemic and hemorrhagic stroke [16].

LVAD use requires vitamin $\mathrm{K}$ antagonist (VKA) anticoagulation (to target INR 2.0-3.0). Deviations below and above target INR are associated with increased risks of ischemic and hemorrhagic stroke, respectively (Fig. 1). One study found that LVAD patients with ischemic

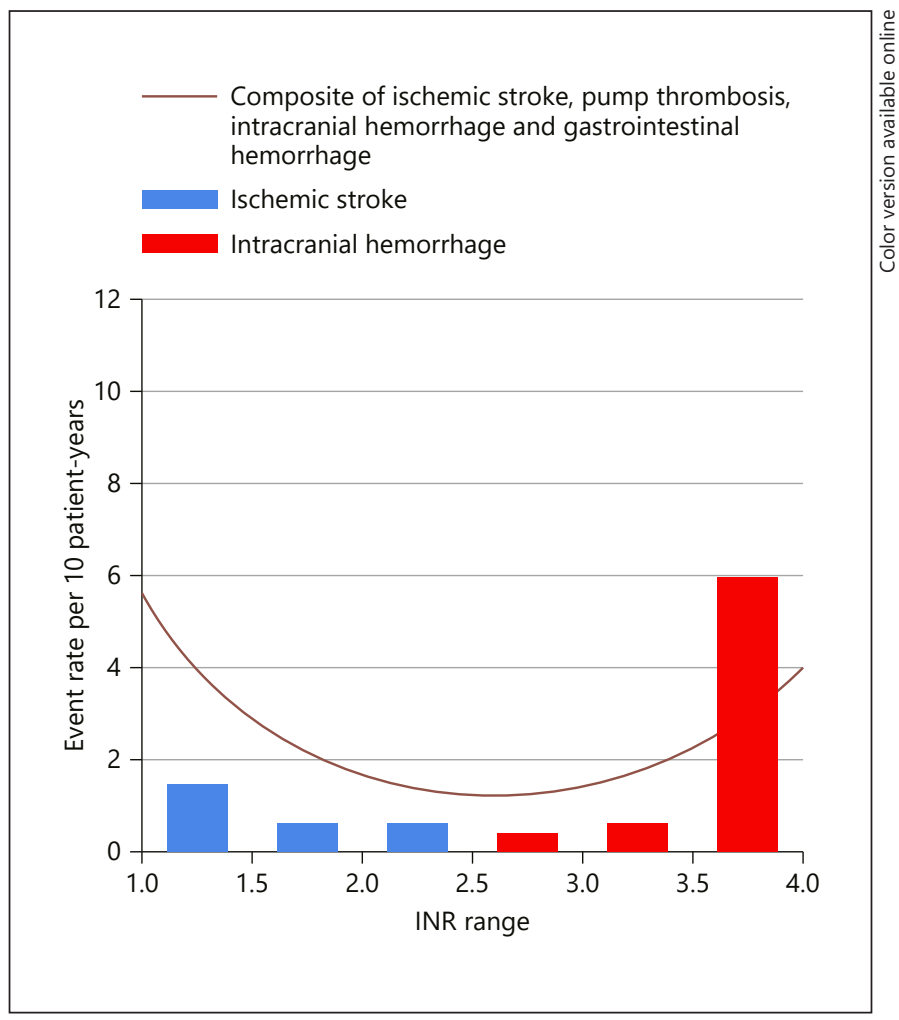

Fig. 1. Rates of ischemic and hemorrhagic complications and associated INR (adapted from [23]).

stroke spent less time in the therapeutic range at 55\%, compared to time in the therapeutic range of $62 \%$ in those without stroke [24]. Another large series found that INR $\geq 3.0$ was independently associated with an increased risk of hemorrhagic stroke [25]. However, therapeutic INR is not consistently associated with a lower risk of stroke. One study found that the mean INR was 2.2 in patients with ischemic events, compared to a mean INR 2.9 in those with hemorrhagic stroke [26].

Female patients with LVADs are at increased risk for hemorrhagic stroke compared to male patients [27]. One series in patients with HeartWare devices found an independent association between hemorrhagic stroke and a mean arterial pressure (MAP) $>90 \mathrm{~mm} \mathrm{Hg}$ [25]. In the ENDURANCE Supplement trial, which included strict blood pressure monitoring with a MAP target of $\leq 85 \mathrm{~mm}$ $\mathrm{Hg}$ by automated cuff and $\leq 90 \mathrm{~mm} \mathrm{Hg}$ by Doppler, there was a $50 \%$ relative risk reduction in stroke from the historical rates reported in the ENDURANCE trial (5.2\% vs. $10.5 \%$ in 12 months, $p=0.02$ ) [28]. Dialysis dependence has also been reported to be associated with a greater risk of hemorrhage in LVAD patients [24]. 


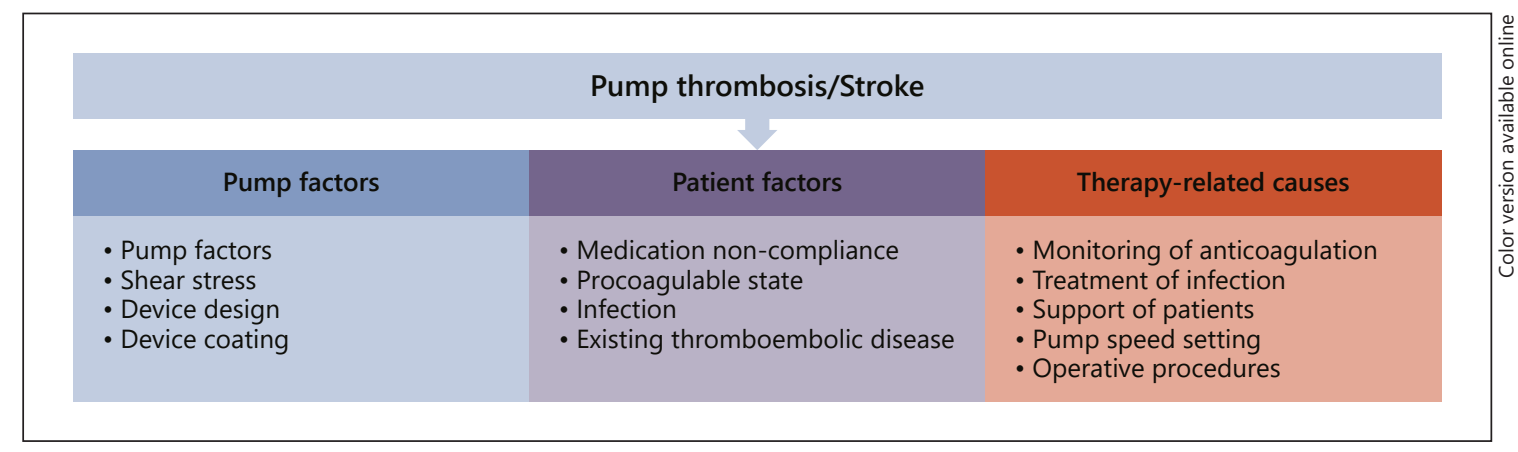

Fig. 2. Etiologies of pump thrombosis and stroke, from Kuehl and Garbade [33].

\section{Pathophysiology}

\section{Ischemic Stroke}

There are multiple elements contributing to thrombotic complications in LVADs related to activation of the extrinsic coagulation pathway through foreign pump materials (hemocompatibility), shear stress, and stasis within a hypokinetic heart, pump circuit or graft site. Concurrent inflammation and infection can also promote coagulation $[29,30]$. Hemolysis caused by shear stress produces ADP leakage from red cells, which in turn promotes platelet activation [29]. Shear stress from altered flow may also promote endothelial damage on native vessels and accelerate atherosclerosis [31, 32]. See Figure 2 for Etiologies of pump thrombosis and stroke.

\section{Hemorrhagic Stroke}

Both exogenous use of antithrombotics in addition to endogenous factors contribute to the risk of hemorrhagic stroke. Altered blood flow patterns may impair cerebral autoregulation and promote endothelial dysfunction through shear stress [34], reduced nitric oxide bioavailability and vascular smooth muscle proliferation [35]. Systemic hemorrhagic complications may be precipitated by acquired von Willebrand's disease, particularly with continuous-flow LVADs. Altered von Willebrand factor (vWF) multimers have been identified in patients with continuous-flow LVADs [36-38], and appear to normalize following device explantation $[38,39]$. In contrast, normal vWF multimers are found in patients with pulsatile-flow LVADs. The breakdown of vWF is caused by shear stress from continuous-flow devices, and results in an acquired deficiency that prevents normal platelet adhesion and leads to systemic bleeding complications [30].

\section{Clinical Evaluation and Treatment of Individuals with LVAD and Stroke}

\section{Physical Exam}

Aspects unique to the physical examination in patients with LVADs may be unfamiliar to many neurologists. Given the continuous blood flow with contemporary LVAD devices, patients will have absent pulses to palpation, no native heart sounds, and undetectable blood pressure by manual technique. Figure 3 outlines the relevant anatomy and pump considerations; Table 2 summarizes key differences in the cardiovascular exam of a patient with an LVAD.

\section{Neuroimaging Investigations - Considerations}

Carotid Doppler Ultrasound

The mechanics of forward blood flow through an LVAD depend on device pump type (i.e., pulsatile vs. continuous flow). In general, an LVAD pumps the blood differently than would a normally functioning native left ventricle. A retrospective review described differences in ultrasound tracings in 13 individuals undergoing carotid Dopplers before versus after LVAD implantation with continuous-flow devices (HeartWare or HeartMate II). Changes described include differences in waveform morphology as well as internal and common carotid artery flow velocities, with increased end diastolic and decreased peak systolic velocities. Mean flow velocities were unchanged following LVAD implantation despite the known changes in pulse pressure [40].

\section{Computed Tomography Angiography}

CT head and CT angiography of the head and neck are widely used in investigating LVAD patients with acute neurologic symptoms. As in non-LVAD patients with 


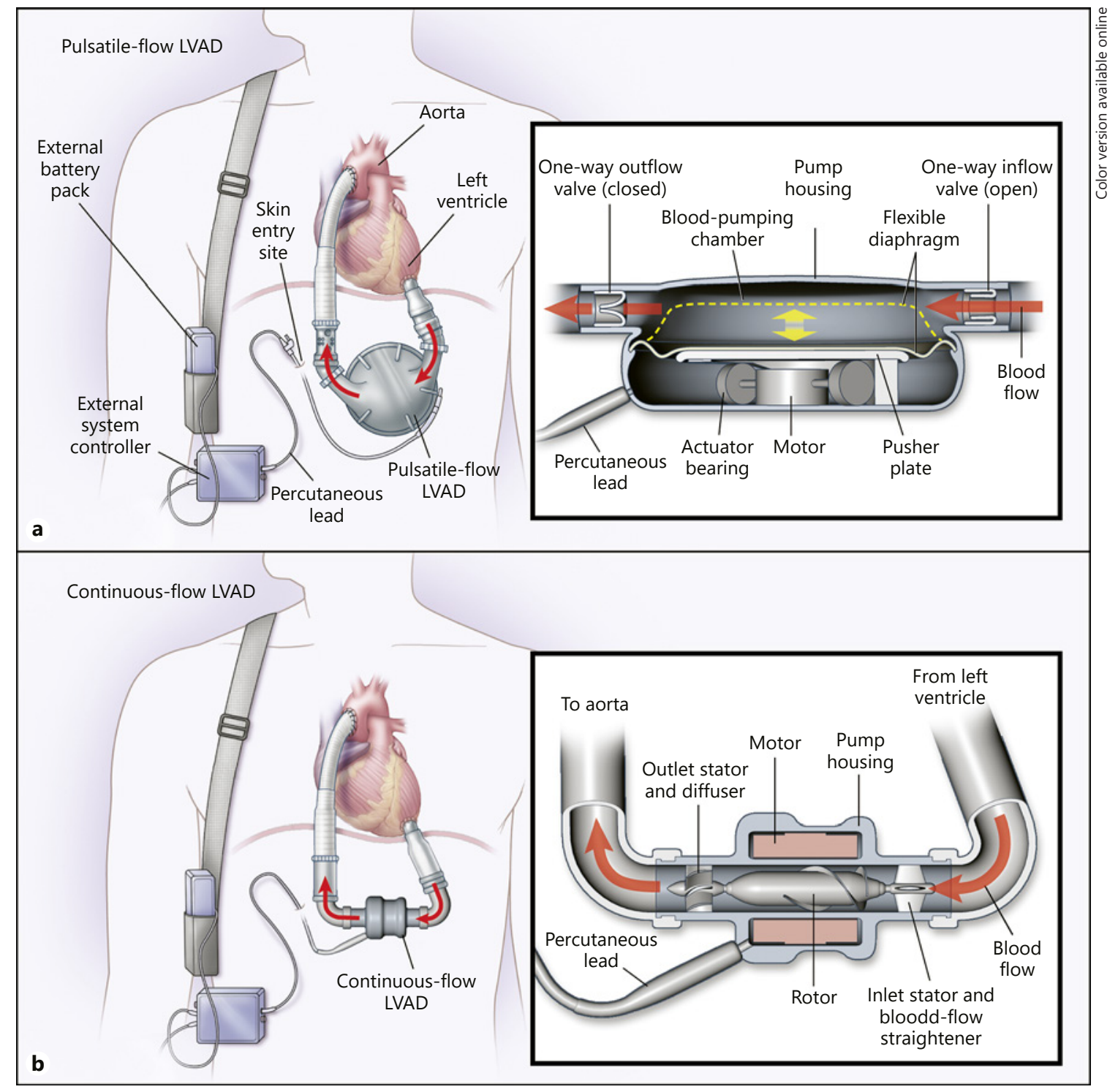

Fig. 3. Pulsatile-flow (a) and continuous-flow (b) LVADs. Original figure from "Advanced Heart Failure Treated with Continuous-Flow Left Ventricular Assist Device" [10] and republished with permission from the investigators. LVADs, left ventricular assist devices.

low cardiac output states (such as congestive heart failure), LVAD patients may appear to have a slower cerebral blood flow and thus may appear to have a poorer collateral circulation depending on device settings and MAP at the time of computed tomography angiography (CTA) acquisition [41]. Multiphase CTA (mCTA) has improved temporal resolution compared to single phase CTA and is therefore a useful technique to overcome poor opacification of intracranial circulation on first pass imaging in patients with low cardiac output [42]. mCTA is often employed in acute stroke imaging with an arterial first phase from the aortic arch to the skull vertex and second and third phases from the skull base to vertex typically acquired at late arterial and early venous time points with little increase in acquisition time or radiation dose [43]. mCTA has been shown to be superior to single phase CTA in the assessment of collateral status [44] which is an independent predictor of outcome post endovascular therapy (EVT) and also superior for the detection of distal intracranial occlusions $[45,46]$. As low cardiac output can interfere with pial arterial filling, an additional fourth phase from the skull base to vertex may be helpful to im- 
Table 2. Practical stroke physical exam tips in LVAD patients

Consideration for the cardiovascular physical exam in LVAD patients

\begin{tabular}{ll}
\hline Pulses & Diminished or absent \\
\hline Blood pressure & Can be measured by \\
& 1. MAP via Doppler ultrasound over the brachial artery and using a manual blood pressure cuff \\
& 2. Placement of an arterial line using ultrasound guidance \\
\hline Heart rate & Can be obtained by doing a 12-lead ECG or device interrogation \\
\hline Cardiac auscultation & Continuous, machine-like noise or hum \\
\hline LVAD external controller & Information displayed: \\
& 1. Pump speed \\
& 2. Flow \\
& 3. Power \\
4. Remaining battery life
\end{tabular}

LVAD, left ventricular assist device; MAP, mean arterial pressure.

prove collateral assessment in low-flow states such as with LVAD patients [43]. Low cardiac output may result in poor opacification of the carotid arteries; however, most current protocols account for this situation by monitoring contrast density in the aorta and timing the CTA to reduce the incidence of poor vessel opacification [47].

\section{Computed Tomography Perfusion}

Computed tomography perfusion (CTP) consists of a temporal sequence of images acquired during the wash-in and wash-out of a bolus of intravenous (IV) contrast. In patients with poor cardiac output, the arterial input function lags behind the true tissue attenuation leading to over-estimation of the infarct core [48] and ischemic penumbra [49]. Indeed, longer time between scan onset and end of the arterial input function has been shown to identify patients with low ejection fraction [50]. The venous output function peak, which serves as a reference for normalization of the perfusion parameters, is not reached within the typical 50-60 s scan window. Truncation of the time attenuation curves leads to inaccurate CTP results [51]. Longer scan acquisition times (which allow complete wash-in and wash-out of contrast) and delay-correction software can assist with this problem [52-54]. Imaging for at least 70-90 s should ensure complete cerebral tissue saturation of iodine [55] and should be adequate for accurate CTP results in most patients with low cardiac output. In the setting of longer image acquisition times, the frequency of image acquisition can be varied to minimize radiation dose. High image acquisition frequency is necessary in the initial period to ensure genera- tion of accurate early-phase arterial and venous concentration curves that allow for optimal calculation of CTP maps [56].

\section{Magnetic Resonance Imaging}

Currently available LVADs are not magnetic resonance imaging compatible given the magnetic components of the pump and metal. This may make the investigation of transient neurologic spells more challenging for neurologists [57].

\section{Primary Stroke Prevention}

LVAD patients with stroke are less often transplanted than those without [58]. Recommendations relevant to primary stroke prevention in this group include (1) optimal blood pressure management with MAP targets of $<90$ $\mathrm{mm} \mathrm{Hg}$; and (2) combination anticoagulation and antiplatelet strategies [25].

Carefully balancing the risks of both thrombosis and bleeding in the LVAD patient population is a challenging feat. We currently lack high-quality evidence to guide specific antithrombotic strategies, although several strategies are commonly adopted. Most centers typically use aspirin in combination with VKAs though some have a preference for VKA alone [13]. The PREVENT trial, looking at early pump thrombosis in the HeartMate II device, used an INR target of 2.0-2.5, whereas all other large trials (ENDURANCE, ADVANCE, ROADMAP, and MOMENTUM) used an INR target of 2.0-3.0 [5,6, $13,14,59]$. One study investigated the safety of lower INR targets (1.5-1.9) in newer centrifugal devices to minimize 
bleeding complications, and showed minimal thrombosis, although this study enrolled only 15 patients [60]. Another small trial comparing anticoagulation with dabigatran (110 mg bid) to VKA was stopped early for safety concerns after half of the 8 patients enrolled in the dabigatran arm experienced thromboembolic events [61].

Aspirin (dosed from 81 to $325 \mathrm{mg}$ daily) is generally the antiplatelet agent of choice. The ADVANCE trial found higher rates of device thrombosis on aspirin doses of $81 \mathrm{mg}$ daily or less compared to $325 \mathrm{mg}$ daily. As a result, subsequent trials (including partway through the ENDURANCE trial) increased the daily aspirin dose to $325 \mathrm{mg}$ daily if tolerated $[6,59]$. Small retrospective reviews suggest that clopidogrel may also be safe from a major bleeding perspective in LVAD patients $[62,63]$.

\section{Acute Stroke Treatment}

The International Society for Heart and Lung Transplantation published guidelines for stroke management in 2013 [64]; here, we integrate additional updated recommendations based on current best practices for stroke treatment.

\section{Thrombolysis}

Anticoagulation protocols post-implantation may vary between centers. In general, patients are put on a low-target IV heparin infusion within $48 \mathrm{~h}$ and are subsequently transitioned to an oral VKA with target INR $2.0-3.0$ and aspirin $[6,13]$. In the immediate postoperative setting, patients with acute ischemic stroke (AIS) are not eligible for tissue plasminogen activator (tPA) given recent surgery. Outside of the implantation window, most LVAD patients are on a combination of antiplatelet therapy and anticoagulation with warfarin, and would therefore have a relative contraindication to tPA in the setting of AIS. One study looking at AIS rates in LVAD patients found that although $65 \%$ those with ischemic stroke had an INR of $<1.7$ at the time of their event, none were deemed eligible for treatment with tPA due to other contraindications, including the perioperative setting, outside of the time or tissue window, and recent hemorrhage [65]. Although tPA is used as a medical treatment for in-pump thrombosis, the low-dose, slow infusion rates typically used in this context are unsuitable for timesensitive therapy for brain ischemia.

\section{Hemorrhagic Stroke}

Acute symptomatic hemorrhagic stroke in LVAD patients should be treated similarly to the non-LVAD population. Attention to rapidly available coagulation param- eters allows decision making around anticoagulation reversal with prothrombin complex concentrate and IV vitamin $\mathrm{K}$ for those patients on warfarin, or IV protamine for those on heparin. Optimal blood pressure control with systolic blood pressure definitely $<180 \mathrm{~mm} \mathrm{Hg}$ and perhaps with a maximum target of $140-160 \mathrm{~mm} \mathrm{Hg}$ (or a MAP target of $<110 \mathrm{~mm} \mathrm{Hg}$ ) for the first 24-48 $\mathrm{h}[66,67]$ is suggested through both conservative (treatment of pain, urinary retention, etc.) and medical (IV blood pressure medications) interventions. In small, asymptomatic intracerebral hemorrhages, the decision regarding anticoagulation management (continuing, holding, or reversal of therapy) should be made on a case-by-case basis through discussion between cardiology and stroke neurology physicians. Following recovery from an intracerebral hemorrhage, the decision of when to restart anticoagulation is made on a case-by-case basis (see "Secondary Stroke Prevention").

\section{Endovascular Therapy}

The reported experience with EVT in this population to date is minimal, though there are no specific LVADrelated clinical considerations that would preclude EVT in an otherwise eligible patient. The interventionalist will need to determine on a case-by-case basis as to whether the aortic graft site would present issues for access and whether an alternative approach (e.g., radial) would be more appropriate than femoral puncture.

The periprocedural and anesthetic risks specific to this patient population should be considered. Multidisciplinary site expertise in LVAD management is ideal, and include input from cardiology/cardiovascular surgery, anesthesiology, perfusion therapy, and LVAD nursing [68]. In addition to standard considerations, LVAD-specific concerns include type of LVAD implanted and current and planned antithrombotic strategy. Right ventricular function should ideally be assessed pre-procedure to guide hemodynamic management, and any recent echocardiograms obtained. Also, important to note is the power source for the LVAD, and to ensure that the batteries are sufficiently charged or the device is connected to another power source. Frequent LVAD monitoring via the patient controller is critical, with careful attention to the displayed values of speed, power, flow, and pulsatility index. The unique physiology in LVAD patients will require adaption of standard monitoring techniques as pulse oximetry and automated blood pressure monitoring may not be reliable in this setting. Blood pressure monitoring should ideally be done using an intra-arterial catheter rather than an automated blood pressure cuff, 
and may require ultrasound guidance for insertion given the lack of peripheral pulses. Noninvasive cerebral oximetry can be considered as a reliable alternative to assess oxygenation [68] and can be confirmed with arterial blood gas sampling. As LVAD pump function is dependent on both preload and afterload, these patients require prompt treatment of intravascular volume depletion, and rapid initiation of vasoactive infusions to manipulate systemic vascular resistance and right heart function.

The reported experience in managing LVAD-related ischemic strokes with EVT is scant. A prospective singlecenter study examined the incidence of AIS with and without large vessel occlusions (LVOs) in 477 LVAD patients between 2004 and 2016. In this cohort, there was a $10.3 \%$ rate of AIS, with $33 \%$ of strokes found to have an LVO on initial CTA (although only about $50 \%$ of stroke patients had vascular imaging). Five of 15 patients with LVO underwent EVT, all with successful recanalization. The other two-thirds of patients with LVO did not undergo EVT for various reasons including: completed infarct or thought to present beyond the time window, minor stroke or rapid improvement, and concomitant intracerebral hemorrhage [65]. In 2 of the 5 EVT patients, the post-interventional course was complicated by recurrent stroke, and another experienced symptomatic hemorrhagic transformation following resumption of anticoagulation [65].

\section{Secondary Stroke Prevention}

Resumption of anticoagulation after stroke in the LVAD population can present a particular clinical challenge as patients are at a high risk of pump thrombosis while off antithrombotics. However, both hemorrhagic transformation of ischemic strokes, or progression/recurrence of hemorrhagic stroke presents a therapeutic dilemma. The experience at one center has been reported recently [69]. Of 283 patients undergoing LVAD placement between 2012 and 2018, 13.8\% experienced an ischemic stroke following implantation. Anticoagulation was resumed immediately in $23 / 38$, held for 1-4 days in 9 patients and longer or not resumed in 6. Despite immediate resumption of anticoagulation in 24 patients, 4 patients had an ischemic stroke, one patient had pump thrombosis and 8 patients had a systemic embolism. That group also experienced $4 \mathrm{ICH}$ and 2 systemic hemorrhages. Of the 15 patients who had delayed resumption of anticoagulation, 3 patients experienced an ischemic event, and 6 experienced hemorrhagic complications. These study findings must be interpreted in context of the limited number of patients, and selection bias given that the risk of recurrent stroke or hemorrhage risk may have influenced the resumption strategy.

Differences in pathophysiology and clinical context make it somewhat challenging to extrapolate the general anticoagulant-associated intracerebral hemorrhage literature to an LVAD population. Multiple observational studies report a robust net benefit balancing risk of thromboembolism with recurrent hemorrhage when restarting anticoagulation within $4-8$ weeks post-ICH, with higher risks of recurrent hemorrhage within the first 2 weeks following $\mathrm{ICH}$, and with lack of resolution of the hemorrhage on neuroimaging [70].

\section{Conclusion}

LVAD implantation is becoming increasingly common and being offered to more medically complex patients. While newer generation LVADs are associated with a lower risk of stroke than their predecessors, LVADs are still associated with high rates of ischemic and hemorrhagic stroke. Neurologists should be familiar with unique characteristics in this patient population related to stroke risks, clinical assessment, and stroke management, both in the acute setting and thereafter.

\section{Acknowledgments}

The authors would like to thank the investigators of "Advanced Heart Failure Treated with Continuous-Flow Left Ventricular Assist Device" [10] for allowing use of their original figure (Fig. 2 in this publication, Fig. 1 in the original article) in this review.

\section{Conflict of Interest Statement}

Alyson R. Plecash, Danielle Byrne, Alana Flexman, Mustafa Toma, and Thalia S. Field declare no potential conflicts of interest.

\section{Funding Sources}

Thalia S. Field is supported by the Michael Smith Foundation for Health Research and the Heart and Stroke Foundation of Canada.

\section{Author Contributions}

Drs Thalia S. Field, Danielle Byrne, Alana Flexman, Mustafa Toma, and Alyson R. Plecash contributed to literature review, manuscript drafting, and editing. 


\section{References}

1 Prinzing A, Herold U, Berkefeld A, Krane M, Lange R, Voss B. Left ventricular assist devices-current state and perspectives. J Thorac Dis. 2016;8(8):E660-6.

2 Rodriguez LE, Suarez EE, Loebe M, Bruckner BA. Ventricular assist devices (VAD) therapy: new technology, new hope? Methodist Debakey Cardiovasc J. 2013 Jan-Mar;9(1):32-7.

3 Lampropulos JF, Kim N, Wang Y, Desai MM, Barreto-Filho JA, Dodson JA, et al. Trends in left ventricular assist device use and outcomes among Medicare beneficiaries, 2004-2011. Open Heart. 2014;1(1):e000109.

4 McCarthy FH, Kobrin D, Rame JE, Groeneveld PW, McDermott KM, Atluri P, et al. Increasing frequency of left ventricular assist device exchanges in the United States. Ann Thorac Surg. 2015;100(5):1660-5; discussion 1665 .

5 Starling RC, Estep JD, Horstmanshof DA, Milano CA, Stehlik J, Shah KB, et al. Risk assessment and comparative effectiveness of left ventricular assist device and medical management in ambulatory heart failure patients: the ROADMAP study 2-year results. JACC Heart Fail. 2017;5(7):518-27.

6 Rogers JG, Pagani FD, Tatooles AJ, Bhat G, Slaughter MS, Birks EJ, et al. Intrapericardial leftventricular assist device for advanced heart failure. N Engl J Med. 2017;376(5):45160.

7 Kirklin JK, Pagani FD, Kormos RL, Stevenson LW, Blume ED, Myers SL, et al. Eighth annual INTERMACS report: special focus on framing the impact of adverse events. J Heart Lung Transplant. 2017;36(10):1080-6.

8 Rose EA, Gelijns AC, Moskowitz AJ, Heitjan DF, Stevenson LW, Dembitsky W, et al. Longterm use of a left ventricular assist device for end-stage heart failure. N Engl J Med. 2001; 345(20):1435-43.

9 Miller LW, Pagani FD, Russell SD, John R, Boyle AJ, Aaronson KD, et al. Use of a continuous-flow device in patients awaiting heart transplantation. N Engl J Med. 2007;357(9): $885-96$.

10 Slaughter MS, Rogers JG, Milano CA, Russell SD, Conte JV, Feldman D, et al. Advanced heart failure treated with continuous-flow left ventricular assist device. N Engl J Med. 2009; 361(23):2241-51.

11 Aaronson KD, Slaughter MS, Miller LW, McGee EC, Cotts WG, Acker MA, et al. Use of an intrapericardial, continuous-flow, centrifugal pump in patients awaiting heart transplantation. Circulation. 2012;125(25):3191-200.

12 Schmitto JD, Pya Y, Zimpfer D, Krabatsch T, Garbade J, Rao V, et al. Long-term evaluation of a fully magnetically levitated circulatory support device for advanced heart failuretwo-year results from the HeartMate $3 \mathrm{CE}$ mark study. Eur J Heart Fail. 2019;21(1):90-7.
13 Maltais S, Kilic A, Nathan S, Keebler M, Emani S, Ransom J, et al. PREVENtion of HeartMate II pump thrombosis through clinical management: the PREVENT multi-center study. J Heart Lung Transpl. 2017;36(1): $1-12$.

14 Mehra MR, Uriel N, Naka Y, Cleveland JC Jr, Yuzefpolskaya M, Salerno CT, et al. A fully magnetically levitated left ventricular assist device - final report. N Engl J Med. 2019; 380(17):1618-27.

15 Kirklin JK, Naftel DC, Myers SL, Pagani FD, Colombo PC. Quantifying the impact from stroke during support with continuous flow ventricular assist devices: an STS INTERMACS analysis. J Heart Lung Transplant. 2020;39(8):782-94.

16 Frontera JA, Starling R, Cho SM, Nowacki AS, Uchino K, Hussain MS, et al. Risk factors, mortality, and timing of ischemic and hemorrhagic stroke with left ventricular assist devices. J Heart Lung Transplant. 2017;36(6): 673-83.

17 Cho SM, Hassett C, Rice CJ, Starling R, Katzan I, Uchino K. What causes LVAD-associated ischemic stroke? Surgery, pump thrombosis, antithrombotics, and infection. ASAIO J. 2019 Nov/Dec;65(8):775-80.

18 Tsiouris A, Heliopoulos I, Mikroulis D, Mitsias PD. Factors defining occurrence of ischemic and hemorrhagic strokes during continuous flow left ventricular assist device support. Gen Thorac Cardiovasc Surg. 2020: 68(4):319-27.

19 Tsiouris A, Heliopoulos I, Mikroulis D, Mitsias PD. Stroke after implantation of continuous flow left ventricular assist devices. J Card Surg. 2019;34(7):541-8.

20 Cornwell WK 3rd, Ambardekar AV, Tran T, Pal JD, Cava L, Lawley J, et al. Stroke incidence and impact of continuous-flow left ventricular assist devices on cerebrovascular physiology. Stroke. 2019;50(2):542-8.

21 Morgan JA, Brewer RJ, Nemeh HW, Gerlach B, Lanfear DE, Williams CT, et al. Stroke while on long-term left ventricular assist device support: incidence, outcome, and predictors. ASAIO J. 2014 May-Jun;60(3):284-9.

22 John R, Naka Y, Park SJ, Sai-Sudhakar C, Salerno C, Sundareswaran KS, et al. Impact of concurrent surgical valve procedures in patients receiving continuous-flow devices. J Thorac Cardiovasc Surg. 2014;147(2):581-9; discussion 589

23 Nassif ME, LaRue SJ, Raymer DS, Novak E, Vader JM, Ewald GA, et al. Relationship between anticoagulation intensity and thrombotic or bleeding outcomes among outpatients with continuous-flow left ventricular assist devices. Circ Heart Fail. 2016;9(5): e002680.

24 Izzy S, Rubin DB, Ahmed FS, Akbik F, Renault S, Sylvester KW, et al. Cerebrovascular accidents during mechanical circulatory support. Stroke. 2018;49:1197-203.
25 Teuteberg JJ, Slaughter MS, Rogers JG, McGee EC, Pagani FD, Gordon R, et al. The HVAD left ventricular assist device: risk factors for neurological events and risk mitigation strategies. JACC Heart Fail. 2015;3(10): $818-28$.

26 Harvey L, Holley C, Roy SS, Eckman P, Cogswell R, Liao K, et al. Stroke after left ventricular assist device implantation: outcomes in the continuous-flow era. Ann Thorac Surg. 2015; 100(2):535-41.

27 Lamba HK, Kim M, Hart L, Chou B, Rao C, Chatterjee $S$, et al. Different risk factors for ischemic and hemorrhagic stroke on continuous flow left ventricular assist device support. J Heart Lung Transplant. 2019;38(4):S171-2.

28 Milano CA, Rogers JG, Tatooles AJ, Bhat G, Slaughter MS, Birks EJ, et al. HVAD: the ENDURANCE supplemental trial. JACC Heart Fail. 2018;6(9):792-802.

29 Koliopoulou A, McKellar SH, Rondina M, Selzman CH. Bleeding and thrombosis in chronic ventricular assist device therapy: focus on platelets. Curr Opin Cardiol. 2016; 31(3):299-307.

30 Eckman PM, John R. Bleeding and thrombosis in patients with continuous-flow ventricular assist devices. Circulation. 2012;125(24): 3038-47.

31 Saltsman JA 3rd, Ravin RA, Faries PL, Tadros R. Rapid progression of carotid artery atherosclerosis and stenosis in a patient with a ventricular assist device. J Vasc Surg Cases Innov Tech. 2016;2(2):40-2.

32 Moulton KS, Li M, Strand K, Burgett S, McClatchey P, Tucker R, et al. PTEN deficiency promotes pathological vascular remodeling of human coronary arteries. JCI Insight. 2018; 3(4):e97228.

33 Kuehl M, Garbade J. The evolution of left ventricular assist devices-a moment to reflect. J Thorac Dis. 2017;9(5):E492-4.

34 Kislitsina ON, Anderson AS, Rich JD, Vorovich EE, Pham DT, Cox JL, et al. Strokes associated with left ventricular assist devices. J Card Surg. 2018;33(9):578-83.

35 Frontera JA. This is your brain on LVAD. J Heart Lung Transplant. 2020;39(3):228-30.

36 Klovaite J, Gustafsson F, Mortensen SA, Sander K, Nielsen LB. Severely impaired von Willebrand factor-dependent platelet aggregation in patients with a continuous-flow left ventricular assist device (HeartMate II). J Am Coll Cardiol. 2009;53(23):2162-7.

37 Heilmann C, Geisen U, Beyersdorf F, Nakamura L, Trummer G, Berchtold-Herz M, et al. Acquired von Willebrand syndrome is an early-onset problem in ventricular assist device patients. Eur J Cardiothorac Surg. 2011;40(6): 1328-233; discussion 1233.

38 Crow S, Milano C, Joyce L, Chen D, Arepally $\mathrm{G}$, Bowles D, et al. Comparative analysis of von Willebrand factor profiles in pulsatile and continuous left ventricular assist device recipients. ASAIO J. 2010 Sep-Oct;56(5):441-5. 
39 Malehsa D, Meyer AL, Bara C, Strüber M. Acquired von Willebrand syndrome after exchange of the HeartMate XVE to the HeartMate II ventricular assist device. Eur J Cardiothorac Surg. 2009;35(6):1091-3.

40 Kabbani LS, Munie S, Lin J, Velez M, Isseh I, Brooks S, et al. Flow patterns in the carotid arteries of patients with left ventricular assist devices. Ann Vasc Surg. 2017;39:182-8.

41 Kim JJ, Dillon WP, Glastonbury CM, Provenzale JM, Wintermark M. Sixty-foursection multidetector CT angiography of carotid arteries: a systematic analysis of image quality and artifacts. AJNR Am J Neuroradiol. 2010;31(1):91-9.

42 Demchuk AM, Menon BK, Goyal M. Comparing vessel imaging: noncontrast computed tomography/computed tomographic angiography should be the new minimum standard in acute disabling stroke. Stroke. 2016;47(1): 273-81.

43 Menon BK, d'Esterre CD, Qazi EM, Almekhlafi M, Hahn L, Demchuk AM, et al. Multiphase CT angiography: a new tool for the imaging triage of patients with acute ischemic stroke. Radiology. 2015;275(2):510-20.

44 Van Den Wijngaard IR, Holswilder G, Wermer MJ, Boiten J, Algra A, Dippel DW, et al. Assessment of collateral status by dynamic CT angiography in acute MCA stroke: timing of acquisition and relationship with final infarct volume. AJNR Am J Neuroradiol. 2016; 37(7):1231-6.

45 Yu AYX, Zerna C, Assis Z, Holodinsky JK, Randhawa PA, Najm M, et al. Multiphase CT angiography increases detection of anterior circulation intracranial occlusion. Neurology. 2016;87:609-16.

46 Byrne D, Sugrue G, Stanley E, Walsh JP, Murphy S, Kavanagh EC, et al. Improved detection of anterior circulation occlusions: the "delayed vessel sign" on multiphase CT angiography. AJNR Am J Neuroradiol. 2017; 38(10):1911-6

47 Saade C, Bourne R, Wilkinson M, Brennan P. Contrast medium administration and parameters affecting bolus geometry in multidetector computed tomography angiography: an overview. J Med Imaging Radiat Sci. 2011; 42(3):113-7.

48 Campbell BC, Christensen S, Levi CR, Desmond PM, Donnan GA, Davis SM, et al. Cerebral blood flow is the optimal CT perfusion parameter for assessing infarct core. Stroke. 2011;42(12):3435-40.
49 Vagal A, Wintermark M, Nael K, Bivard A, Parsons M, Grossman AW, et al. Automated CT perfusion imaging for acute ischemic stroke: pearls and pitfalls for real-world use. Neurology. 2019;93(20):888-98.

50 Garcia-Esperon C, Spratt NJ, Gangadharan S, Miteff F, Bivard A, Lillicrap T, et al. Computed tomography perfusion identifies patients with stroke with impaired cardiac function. Stroke. 2020;51(2):498-503.

51 Copen WA, Deipolyi AR, Schaefer PW, Schwamm LH, González RG, Wu O. Exposing hidden truncation-related errors in acute stroke perfusion imaging. AJNR Am J Neuroradiol. 2015;36(4):638-45.

52 Kudo K, Sasaki M, Yamada K, Momoshima S, Utsunomiya $\mathrm{H}$, Shirato $\mathrm{H}$, et al. Differences in CT perfusion maps generated by different commercial software: quantitative analysis by using identical source data of acute stroke patients. Radiology. 2010;254(1):200-9.

53 Schaefer PW, Mui K, Kamalian S, Nogueira RG, Gonzalez RG, Lev MH. Avoiding "pseudo-reversibility" of CT-CBV infarct core lesions in acute stroke patients after thrombolytic therapy: the need for algorithmically "delay-corrected" CT perfusion map postprocessing software. Stroke. 2009;40: 2875-8.

54 Konstas AA, Lev MH. CT perfusion imaging of acute stroke: the need for arrival time, delay insensitive, and standardized postprocessing algorithms? Radiology. 2010;254(1):22-5.

55 Wintermark M, Albers GW, Alexandrov AV, Alger JR, Bammer R, Baron JC, et al. Acute stroke imaging research roadmap. AJNR Am J Neuroradiol. 2008;29(5):e23-30.

56 Heit JJ, Wintermark M. Perfusion computed tomography for the evaluation of acute ischemic stroke: strengths and pitfalls. Stroke. 2016;47(4):1153-8

57 Coutts SB, Moreau F, Asdaghi N, Boulanger $\mathrm{J}-\mathrm{M}$, Camden M-C, Campbell BCV, et al. Rate and prognosis of brain ischemia in patients with lower-risk transient or persistent minor neurologic events. JAMA Neurol. 2019; 76(12):1439-45.

58 Acharya D, Loyaga-Rendon R, Morgan CJ, Sands KA, Pamboukian SV, Rajapreyar I, et al. INTERMACS analysis of stroke during support with continuous-flow left ventricular assist devices: risk factors and outcomes. JACC Heart Fail. 2017;5(10):703-11.

59 Najjar SS, Slaughter MS, Pagani FD, Starling RC, McGee EC, Eckman P, et al. An analysis of pump thrombus events in patients in the HeartWare ADVANCE bridge to transplant and continued access protocol trial. J Heart Lung Transplant. 2014;33(1):23-34.
60 Netuka I, Ivák P, Tučanová Z, Gregor S, Szárszoi O, Sood P, et al. Evaluation of lowintensity anti-coagulation with a fully magnetically levitated centrifugal-flow circulatory pump-the MAGENTUM 1 study. J Heart Lung Transplant. 2018;37(5):579-86.

61 Andreas M, Moayedifar R, Wieselthaler G, Wolzt M, Riebandt J, Haberl T, et al. Increased thromboembolic events with dabigatran compared with vitamin $\mathrm{K}$ antagonism in left ventricular assist device patients. Circ Heart Fail. 2017;10:e003709.

62 McDavid A, MacBrair K, Emani S, Yu L, Lee PHU, Whitson BA, et al. Anticoagulation management following left ventricular assist device implantation is similar across all provider strategies. Interact Cardiovasc Thorac Surg. 2018;26(1):60-5.

63 Bhatia A, Sayer G, Adatya S, Kim G, Sarswat $\mathrm{N}$, Ota $\mathrm{T}$, et al. Clopidogrel does not increase incidence of bleeding in LVAD patients. J Heart Lung Transplant. 2016;35(4):S239.

64 Feldman D, Pamboukian SV, Teuteberg JJ, Birks E, Lietz K, Moore SA, et al. The 2013 international society for heart and lung transplantation guidelines for mechanical circulatory support: executive summary. J Heart Lung Transplant. 2013;32(2):157-87.

65 Rice CJ, Cho SM, Zhang LQ, Hassett C, Starling RC, Uchino K. The management of acute ischemic strokes and the prevalence of large vessel occlusion in left ventricular assist device. Cerebrovasc Dis. 2018;46(5-6):213-7.

66 Shoamanesh Co-Chair A, Patrice Lindsay M, Castellucci LA, Cayley A, Crowther M, de Wit $\mathrm{K}$, et al. Canadian stroke best practice recommendations: management of spontaneous intracerebral hemorrhage, 7 th edition update 2020. Int J Stroke. 2021;16(3):321-41.

67 Shi L, Xu S, Zheng J, Xu J, Zhang J. Blood pressure management for acute intracerebral hemorrhage: a meta-analysis. Sci Rep. 2017;7: $1-8$.

68 Chung M. Perioperative management of the patient with a left ventricular assist device for noncardiac surgery. Anesth Analg. 2018; 126(6):1839-50.

69 Ibeh C, Tirschwell DL, Mahr C, Li S, Beckman JA, Creutzfeldt CJ. Acute anticoagulation after ischemic stroke in patients with left ventricular assist devices. ASAIO J. 2021;67(3): e74-76.

70 Sembill JA, Kuramatsu JB, Schwab S, Huttner HB. Resumption of oral anticoagulation after spontaneous intracerebral hemorrhage. Neurol Res Pract. 2019;1:12. 